\title{
Formation and resuscitation of 'non- culturable' cells of Rhodococcus rhodochrous and Mycobacterium tuberculosis in prolonged stationary phase
}

\author{
M. O. Shleeva, ${ }^{1}$ K. Bagramyan, ${ }^{1}$ M. V. Telkov, ${ }^{1}$ G. V. Mukamolova, ${ }^{1,2}$ \\ M. Young, ${ }^{2}$ D. B. Kell ${ }^{2}$ and A. S. Kaprelyants ${ }^{1}$
}

Author for correspondence: Arseny Kaprelyants. Tel: +795954 40 47. Fax: +7959542732. e-mail: arseny@inbi.ras.ru

1 Bakh Institute of Biochemistry, Moscow, Russia

2 Institute of Biological Sciences, University of Wales, Aberystwyth, UK
After growth of Rhodococcus rhodochrous in Sauton's medium, and further incubation for about $60 \mathrm{~h}$ in stationary phase, there was a transient (up to 5 log) decrease in the c.f.u. count, whereas the total count remained similar to its initial value. At the point of minimal viability, the most probable number (MPN) count was 10 times greater than the c.f.u. count. This difference was further magnified by 3-4 logs (giving values close to the total count) by incorporating supernatant taken from growing cultures. A small protein similar to Rpf (resuscitation-promoting factor of Micrococcus luteus) appeared to be responsible for some of the activity in the culture supernatant. The formation of 'non-culturable' cells of the 'Academia' strain of Mycobacterium tuberculosis was similarly observed following growth in Sauton's medium containing Tween 80 in sealed culture vessels, and further incubation for an extended stationary phase. This resulted in the formation, 4-5 months postinoculation, of a homogeneous population of ostensibly 'non-culturable' cells (zero c.f.u.). Remarkably, the MPN count for these cultures was $1^{5}$ organisms $\mathrm{ml}^{-1}$, and this value was further increased by one log using supernatant from an actively growing culture. Populations of 'non-culturable' cells of Mycobacterium tuberculosis were also obtained by the filtration of 'clumpy' cultures, which were grown in the absence of Tween 80 . These small cells could only be grown in liquid medium (MPN) and their viability was enhanced by the addition of culture supernatant or Rpf. The 'non-culturable' cells that accumulated during prolonged stationary phase in both the $R$. rhodochrous and the Mycobacterium tuberculosis cultures were small ovoid and coccoid forms with an intact permeability barrier, but with undetectable respiratory activity. The authors consider these non-culturable bacteria to be dormant. The observed activity of culture supernatants and Rpf with 'non-culturable' bacterial suspensions invites the speculation that one, or more, of the cognate Mycobacterium tuberculosis Rpf-like molecule(s) could be involved in mechanisms of latency and reactivation of tuberculosis in vivo.

Keywords: dormancy, Nocardiaceae, VBNC, Rpf, Micrococcus luteus

\section{INTRODUCTION}

It is generally believed that pathogenic, slow-growing

Abbreviations: $\mathrm{ADC}$, albumen, glucose and $\mathrm{NaCl}$; CTC, 5-cyano-2,3-ditolyl tetrazolium chloride; MPN, most probable number; Rpf, resuscitationpromoting factor; SN, supernatant; VBNC, viable but non-culturable. mycobacteria, such as Mycobacterium tuberculosis or Mycobacterium leprae, can persist for long periods of time in vivo after initial infection, by passing into a dormant or non-replicating persistent state (Gangadharam, 1995; Parrish et al., 1998; Wayne \& Sohaskey, 2001). Such dormant Mycobacterium tuberculosis cells can persist for many years in the host, causing latent 
tuberculosis before their transition to active, dividing bacteria occurs and disease is activated. It is perhaps surprising that the existence of a dormant state for mycobacteria either in vitro or in vivo has not yet been convincingly established. The most widely accepted in vitro model for the transition of Mycobacterium tuberculosis to an apparently dormant state is Wayne's model, in which cells are subjected to gradual oxygen depletion. This results in the formation of an anaerobic, drug-resistant, non-replicating state (Wayne, 1994; Wayne \& Hayes, 1996). Under these conditions, the putatively dormant bacteria shut down protein synthesis, but this restarts after the reintroduction of oxygen (Hu et al., 1998). A similar phenomenon has been found for Mycobacterium smegmatis (Dick et al., 1998) and Mycobacterium bovis (Lim et al., 1999). Mycobacterium tuberculosis, Mycobacterium smegmatis and Mycobacterium bovis revealed similar changes during the transition to anaerobic persistence. For example, the activity of some dehydrogenases was induced to maintain the NAD pool under anaerobiosis, an $\alpha$-crystallin-like protein was expressed, and cell-wall thickening occurred in Mycobacterium tuberculosis and Mycobacterium bovis BCG (Cunningham \& Spreadbury, 1998; Hutter \& Dick, 1998; Lim et al., 1999). Another approach to obtain dormant Mycobacterium tuberculosis in vivo is the Cornell mouse model. Mice infected by Mycobacterium tuberculosis are treated with antibiotics, after which the number of culturable cells extractable from organs falls to zero (Wayne, 1994). Notably, mycobacterial DNA can still be detected in such apparently 'sterile' tissues and quantitative PCR has revealed the presence of amounts of DNA equivalent to about $10^{5}$ organisms (g tissue) ${ }^{-1}$ (de Wit et al., 1995). Subsequently, culturable Mycobacterium tuberculosis cells reappear, either spontaneously or in response to immune suppression (Flynn \& Chan, 2001; McCune et al., 1966). The essential difference between the two models is the maintenance of the high culturability of Mycobacterium tuberculosis cells in Wayne's model and the presence of a non-culturable state in the Cornell model. However, the absence of experiments in which the presumably dormant bacteria in the Cornell model can be resuscitated and enumerated in vitro creates some difficulties in data interpretation. On the one hand, PCR may detect a substantial population of non-culturable (dormant) cells that subsequently resuscitate in vivo. On the other hand, it may detect a large proportion of dead cells, in which case the re-emergence of colony-forming units would simply reflect the re-growth of a very small number of viable cells left after treatment with antibiotics (Kell et al., 1998). These two possibilities have not yet been distinguished experimentally.

Micrococcus luteus is a member of the Actinomycetales and is therefore related to Mycobacterium tuberculosis. This organism can persist in a dormant state, following growth to stationary phase in batch culture and starvation for several months in the spent growth medium (Kaprelyants et al., 1993; Kaprelyants \& Kell, 1993a). Dormant Micrococcus luteus cells have lost the ability to grow on agar plates; however, the addition of supernatant (SN) from growing Micrococcus luteus cultures to dormant cells has been shown to restore the ability to divide freely, thereby resuscitating the cells to normal, colony-forming bacteria (Kaprelyants \& Kell, 1996; Kaprelyants et al., 1994). Micrococcus luteus cells secrete a resuscitation-promoting factor (Rpf), which promotes the resuscitation of dormant cells (Kaprelyants et al., 1996). Rpf has subsequently been shown to be a small protein that is active at picomolar concentrations (Kaprelyants et al., 1999; Mukamolova et al., 1998). Genes encoding Rpf-like proteins are widely distributed throughout the Actinomycetales; database searches have revealed that similar genes are present in mycobacteria, corynebacteria and streptomycetes (Kell \& Young, 2000). If, as seems likely, the Rpf-like proteins of these organisms have similar functional roles to that of Micrococcus luteus Rpf, we may be able to predict the existence of a 'non-culturable', dormant state in other members of the Actinomycetales.

The aim of the present study was to find conditions for the in vitro transition of two organisms belonging to the Corynebacterineae (fast-growing $R$. rhodochrous and slow-growing Mycobacterium tuberculosis) to a 'nonculturable' (possibly dormant) state. We also tested the hypothesis that secreted bacterial proteins may stimulate resuscitation of these two organisms.

\section{METHODS}

Organisms and media. Rhodococcus rhodochrous NCIMB 13805 was grown aerobically at $37^{\circ} \mathrm{C}$ in shake flasks $(125 \mathrm{ml}$ medium in $750 \mathrm{ml}$ flasks, agitation at 200 r.p.m.) in nutrient broth E (Lab M) or in modified Sauton's medium. The latter contained (per litre): $\mathrm{MgSO}_{4} .7 \mathrm{H}_{2} \mathrm{O}, 0.5 \mathrm{~g}$; L-asparagine, $4 \mathrm{~g}$; glycerol, $60 \mathrm{ml}$; iron ammonium citrate, $0.05 \mathrm{~g}$; sodium citrate, $2 \mathrm{~g} ; \mathrm{ZnSO}_{4} .7 \mathrm{H}_{2} \mathrm{O}, 0.1 \mathrm{ml}$ of a $1 \%$ solution in $\mathrm{H}_{2} \mathrm{O}$; $\mathrm{K}_{2} \mathrm{HPO}_{4} .3 \mathrm{H}_{2} \mathrm{O}, 7 \cdot 75 \mathrm{~g} ; \mathrm{NaH}_{2} \mathrm{PO}_{4} .2 \mathrm{H}_{2} \mathrm{O}, 4 \cdot 25 \mathrm{~g}$. When the culture had reached stationary phase, agitation was continued at $37^{\circ} \mathrm{C}$ for up to 2 weeks. The avirulent Academia strain of Mycobacterium tuberculosis (Ogloblina \& Ravich-Birger, 1958) was obtained from the Phthysiopulmonology Center (Moscow). Cells were grown in loosely capped (plastic screwcaps) $14 \mathrm{ml}$ test tubes containing $2 \mathrm{ml}$ of unmodified Sauton's medium supplemented with albumen, glucose and $\mathrm{NaCl}$ (ADC), without shaking at $37^{\circ} \mathrm{C}$ (Connell, 1994). Cultures were held in stationary phase at $37^{\circ} \mathrm{C}$ for up to 8 months. To obtain a population of single cells, cultures were passed through two Schott glass filters $(50 \mu \mathrm{m}$ and $20 \mu \mathrm{m}$, respectively) followed by a series of five nitrocellulose filters $(4 \mu \mathrm{m}$, $2 \mu \mathrm{m}, 1.5 \mu \mathrm{m}, 0.8 \mu \mathrm{m}$ and $0.45 \mu \mathrm{m}$, respectively; Whatman). To produce less-aggregated and oxygen-starved populations, Mycobacterium tuberculosis cells were also grown in $200 \mathrm{ml}$ of the same medium in the presence of $0.05 \%$ Tween 80 , with shaking (150-200 r.p.m.) in $750 \mathrm{ml}$ flasks fitted with rubber seals. Needles were employed for sterile sampling without oxygen input.

Scanning electron microscopy. Cells were fixed for $30 \mathrm{~min}$ in $3 \%$ glutaraldehyde, followed by treatment with $0.1 \mathrm{M}$ sodium cacodylate buffer (pH 7-2). Samples were air-dried, sputtercoated with $20 \mathrm{~nm}$ Au particles and examined using a GSM-840A (Japan) scanning electron microscope. 
Respiratory activity, membrane energization and the permeability barrier. The respiratory activity of the bacterial cells was determined by using the fluorescent redox dye CTC (5cyano-2,3-ditolyl tetrazolium chloride; Polysciences), as described by Kaprelyants \& Kell (1993b). Briefly, the bacteria were incubated in the presence of $4 \mathrm{mM}$ CTC (freshly prepared in $10 \mathrm{mM}$ sodium phosphate buffer, $\mathrm{pH} 7 \cdot 0$ ) for $30 \mathrm{~min}$ at $37^{\circ} \mathrm{C}$. Fluorescence was monitored with a Nikon fluorescence microscope with excitation at 530-550 nm. Cells were stained with propidium iodide $(4 \mu \mathrm{M}$ in phosphate buffer), to assess the state of the membrane permeability barrier. Rhodamine 123 was used to monitor membrane energization, as previously described (Kaprelyants \& Kell, 1992). Rhodamine 123 accumulation was sensitive to the uncoupler carbonylcyanide-3-chlorophenyl-hydrazone (CCCP). Cells were studied under the fluorescence microscope (excitation at $510-560 \mathrm{~nm}$ and emission at $590 \mathrm{~nm}$ for propidium iodide; excitation at $450-490 \mathrm{~nm}$ and emission at $520 \mathrm{~nm}$ for rhodamine 123).

Estimation of the redox potential. The changes in the oxidation/reduction potential of the growth medium during $R$. rhodochrous growth were measured in undiluted samples $(3 \mathrm{ml})$ taken from the bacterial culture. Measurement of the redox potential was done with a platinum electrode (and an $\mathrm{AgCl}$ reference electrode; normal potential at $20{ }^{\circ} \mathrm{C}$ was $201 \pm 2 \mathrm{mV}$ ) by using an I-130.2M ionometer (Soyusanalitpribor) under aerobic conditions at $20^{\circ} \mathrm{C}$, with intensive stirring until a constant value was reached.

Assessment of cell viability. Bacterial suspensions were serially diluted in growth medium and duplicate $100 \mu \mathrm{l}$ samples were plated in triplicate onto agar-solidified nutrient broth E (for R. rhodochrous) or onto agar-solidified, ADCsupplemented Sauton's medium (for Mycobacterium tuberculosis). Plates were incubated at $37^{\circ} \mathrm{C}$. After 5 days of growth for $R$. rhodochrous and after 2 months of growth for Mycobacterium tuberculosis, c.f.u. values were enumerated. The detection limit was $5 \times 10^{0}$ c.f.u. $\mathrm{ml}^{-1}$. The same serially diluted samples of Mycobacterium tuberculosis were also employed for resuscitation and most probable number (MPN) assays. Using a fresh pipette tip each time, $100 \mu \mathrm{l}$ samples were taken from each dilution. Ten of these samples were added to 10 replicate $10 \mathrm{ml}$ Pyrex screw-cap tubes, each containing $2 \mathrm{ml}$ Sauton's medium supplemented with ADC. Rpf was added to five of the tubes to give a final concentration of $100 \mathrm{pM}$. Five additional samples were added to five replicate $10 \mathrm{ml}$ Pyrex screw-cap tubes containing $2 \mathrm{ml}$ filter-sterilized $\mathrm{SN}$ taken from cultures of Mycobacterium tuberculosis in the lateexponential phase of growth (30-40 days post-inoculation). The 15 tubes for each dilution were incubated at $37^{\circ} \mathrm{C}$ without shaking for 2 months.

Resuscitation and MPN assays for $R$. rhodochrous were performed in 48-well plastic plates ('Corning') containing either $0.5 \mathrm{ml}$ modified Sauton's medium (see above) or $0.5 \mathrm{ml}$ filter-sterilized SN taken from $R$. rhodochrous cultures. Some wells contained 125 pM Rpf. All wells were supplemented with $0.5 \%$ yeast extract (LabM). Appropriate serial dilutions of $R$. rhodochrous cells $(50 \mu \mathrm{l})$ were added to each well. Plates were incubated at $37^{\circ} \mathrm{C}$, with agitation at 150 r.p.m. for 5 days. Tubes or wells with visible bacterial growth were counted as positive, and MPN values were calculated using standard statistical methods (de Man, 1975).

Spent medium preparation. SNs were obtained from $R$. rhodochrous and Mycobacterium tuberculosis cultures harvested at the times indicated in Results. The $R$. rhodochrous
SN was subjected to centrifugation $(12000 \mathrm{~g}, 20 \mathrm{~min})$. The SNs were sterilized by passage through a $0.22 \mu \mathrm{m}$ filter (Whatman) before use. Proteinase treatment of the SNs was performed at $37^{\circ} \mathrm{C}$ by adding trypsin $\left(200 \mu \mathrm{g} \mathrm{ml}^{-1}\right)$ or proteinase $\mathrm{K}$ immobilized on acrylic beads $\left(0.04 \mathrm{U} \mathrm{ml}^{-1}\right.$; Sigma), followed by the addition of trypsin inhibitor $\left(400 \mu \mathrm{g} \mathrm{ml}^{-1}\right)$ to samples containing trypsin. The time of incubation was $30 \mathrm{~min}$ for trypsin-treated SNs and $3 \mathrm{~h}$ for proteinase-K-treated SNs.

Bacterial counts. The total number of Mycobacterium tuberculosis cells was determined microscopically using a Helber's chamber. A minimum of 100 bacteria was counted and the SD of the total counts was not in excess of $20 \%$.

Preparation of recombinant Micrococcus luteus Rpf. The Rpf protein of Micrococcus luteus (histidine-tagged recombinant form) was obtained as described by Mukamolova et al. (1998). Mono Q ion-exchange purification was omitted in some experiments. The purified protein was stored in $10 \mathrm{mM}$ Tris $/ \mathrm{HCl}(\mathrm{pH} 7 \cdot 4)$ containing $50 \%(\mathrm{v} / \mathrm{v})$ glycerol at $-20{ }^{\circ} \mathrm{C}$ for up to 2 weeks, and the protein concentration was determined spectrophotometrically. Before use, all preparations were screened for growth-promoting activity using a small inoculum of Micrococcus luteus, as described by Mukamolova et al. (1998). Some preparations had poor activity; only those with substantial activity were employed for these experiments.

Preparation of antibody columns. Rabbits were immunized three times at 3-week intervals by subcutaneous injection with $1 \mathrm{ml}$ of a $50 \%(\mathrm{v} / \mathrm{v})$ mixture of $\mathrm{Rpf}\left(1 \mathrm{mg} \mathrm{ml}^{-1}\right.$ in water $)$ and incomplete Freund's adjuvant (Sigma). Serum was collected 10 days after the last immunization, and the immunoglobulin fraction was purified by a standard protocol using polyethylene glycol. Similar methods were used by Micropharm (Newcastle Emlyn, Carmarthenshire, UK) to raise and purify antibodies to a truncated version of $\mathrm{Rpf}$ (residues $\mathrm{A}_{39}-\mathrm{L}_{115}$ ) in sheep. Immunoglobulins were conjugated to $\mathrm{CNBr}$-activated Sepharose 4B (Sigma) (Osterman, 1985).

\section{RESULTS}

\section{Formation of 'non-culturable' cells of $\boldsymbol{R}$. rhodochrous}

$R$. rhodochrous cells were initially grown in the rich medium, nutrient broth $\mathrm{E}$, for different times and then employed as an inoculum $\left(10^{6}\right.$ cells $\left.\mathrm{ml}^{-1}\right)$ for growth in modified Sauton's minimal medium (the elevated concentrations of phosphates in this medium stabilize the culture $\mathrm{pH}$ during stationary phase). Stationary phase was established within about $24 \mathrm{~h}$, and further incubation resulted in a gradual decrease of the c.f.u. value, starting about $30 \mathrm{~h}$ post-inoculation (Fig. 1a). A minimum value was reached between 80 and 100 h postinoculation, after which time the c.f.u. value gradually recovered until it finally exceeded the initial value. After the initial growth phase, the total count (estimated microscopically; data not shown) and the optical density remained almost constant, except that the optical density fell slightly, coincident with the period of non-culturability (Fig. 1a). The precise time at which culturability (c.f.u. counts) reached its minimum was variable from one experiment to another, but it correlated with a transient increase in the redox potential of the culture (Fig. 1b). The extent of the transient loss of culturability depended on the age of the inoculum. The 
(a)

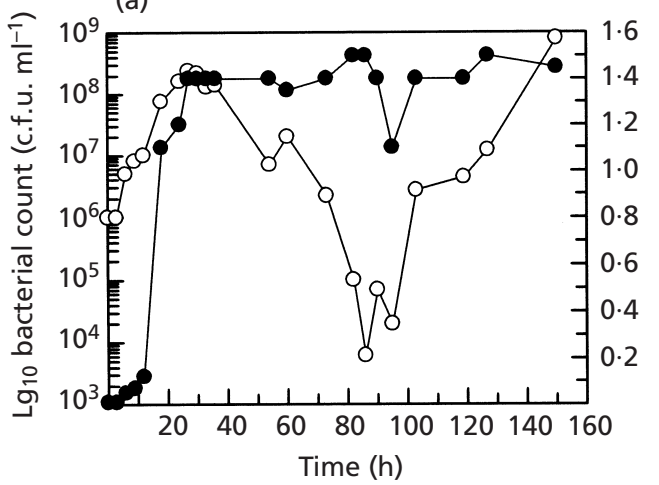

(b)

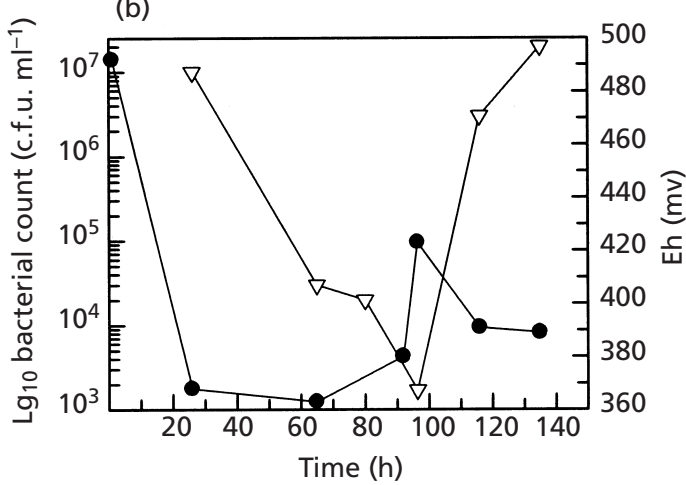

(c)

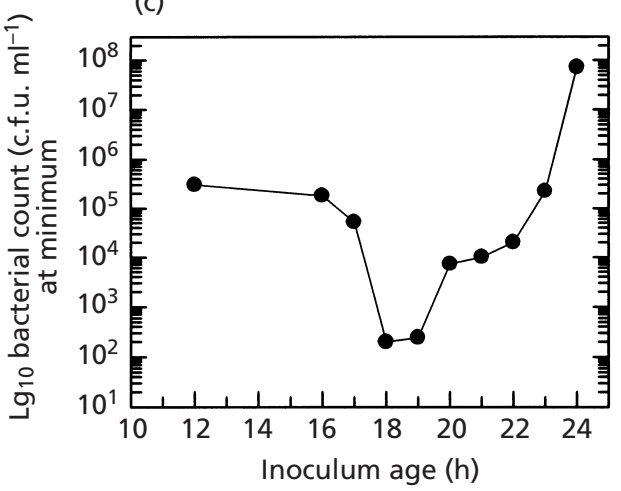

Fig. 1. $R$. rhodochrous cells grown in batch culture in modified Sauton's medium show a transient loss of culturability. A culture in nutrient broth $\mathrm{E}$ (inoculated $18 \mathrm{~h}$ previously) was employed as inoculum $\left(10^{6}\right.$ cells $\left.\mathrm{ml}^{-1}\right)$ in (a) and (b) and the number of colony-forming units were monitored over time. The $\mathrm{OD}_{600}$ (a) and Eh (b) were also monitored. In (c), the effect of inoculum age on the maximum loss of culturability is shown. This experiment was repeated 15 times; the results of a typical experiment are shown. For further details see Methods. The SD values for c.f.u. determinations were generally within the limits almost covered by the symbols in the Figure; for example, they were $38 \%, 3 \%$ and $11 \%$ for the points at $24 \mathrm{~h}, 48 \mathrm{~h}$ and $96 \mathrm{~h}$, respectively, in part (a). The SD values on measurements of Eh and $\mathrm{OD}_{600}$ in stationary phase were about $3 \%$ and $5 \%$. (a) $\mathrm{OD}_{600}$ value; $O$, c.f.u. value. (b) $\bullet$, Eh value; $\nabla$, c.f.u. value.

largest effect was observed with an inoculum taken from a culture that had itself been inoculated some 18-19 h previously (Fig. 1c). Optimum conditions for observing the loss of culturability (i.e. the biggest effect) were as indicated in Methods. However, loss of culturability (a)

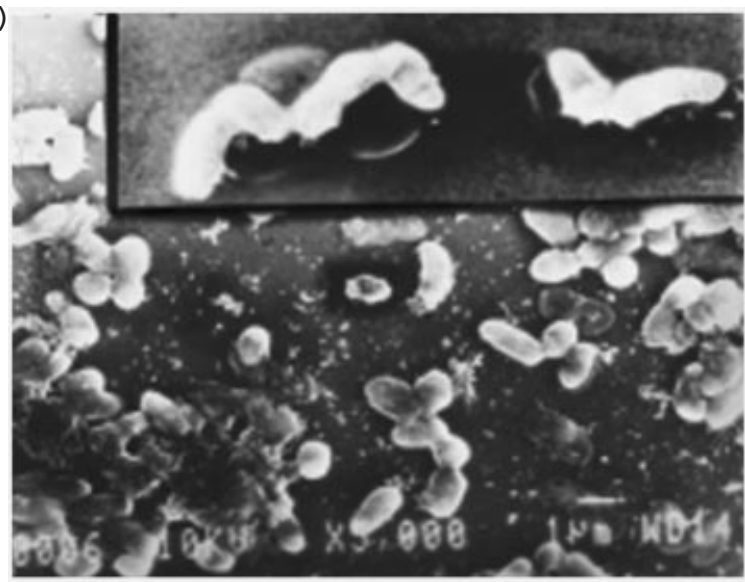

(b)

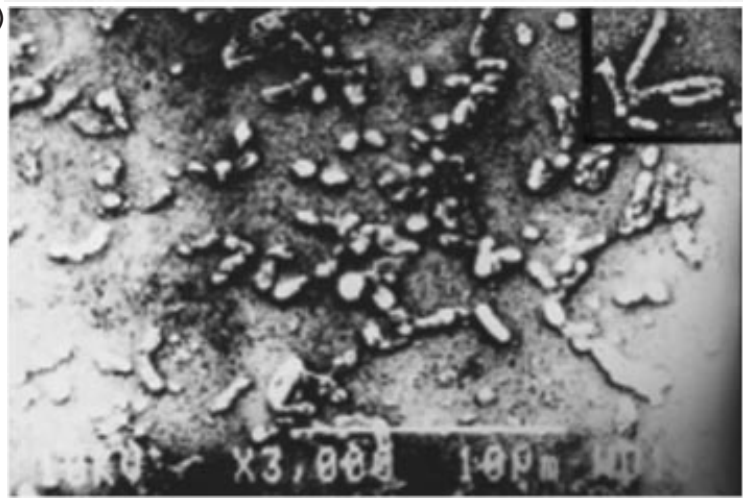

Fig. 2. Scanning electron micrographs of populations of 'non-culturable' cells of $R$. rhodochrous and Mycobacterium tuberculosis. $R$. rhodochrous cells (a) were grown in modified Sauton's medium and sampled when the c.f.u. value had attained its minimum (see Fig. 1). Mycobacterium tuberculosis cells (b) were grown for 4 months in ADC-supplemented, unmodified Sauton's medium, as described in Methods, and cells that were not retained by a $2 \mu \mathrm{m}$ filter were prepared for electron microscopy. The insets in (a) and (b) are bacteria from exponentially growing cultures of $R$. rhodochrous $(20 \mathrm{~h}$ postinoculation) and Mycobacterium tuberculosis (1 month postinoculation), respectively.

was observed over a range of agitation speeds, between 100 and 250 r.p.m., and at culture volumes corresponding to between $12 \%$ and $25 \%$ of the volume of the culture flask.

Microscopic examination of the cells during the period of non-culturability revealed that the majority were ovoid or coccoid forms; this morphology contrasted with the characteristic elongated curved rod shape of exponentially growing cells (Fig. 2a). Only about $10 \%$ of the cells in the population were metabolically active [according to fluorescence microscopy with Rhodamine 123 as an indicator of membrane energization (Kaprelyants \& Kell, 1992) and CTC as an indicator of respiratory activity (Kaprelyants \& Kell, 1993b)]. Between $80 \%$ and $90 \%$ of the cells failed to stain with propidium iodide, indicating that their membrane permeability barrier was intact (Davey et al., 1999). 

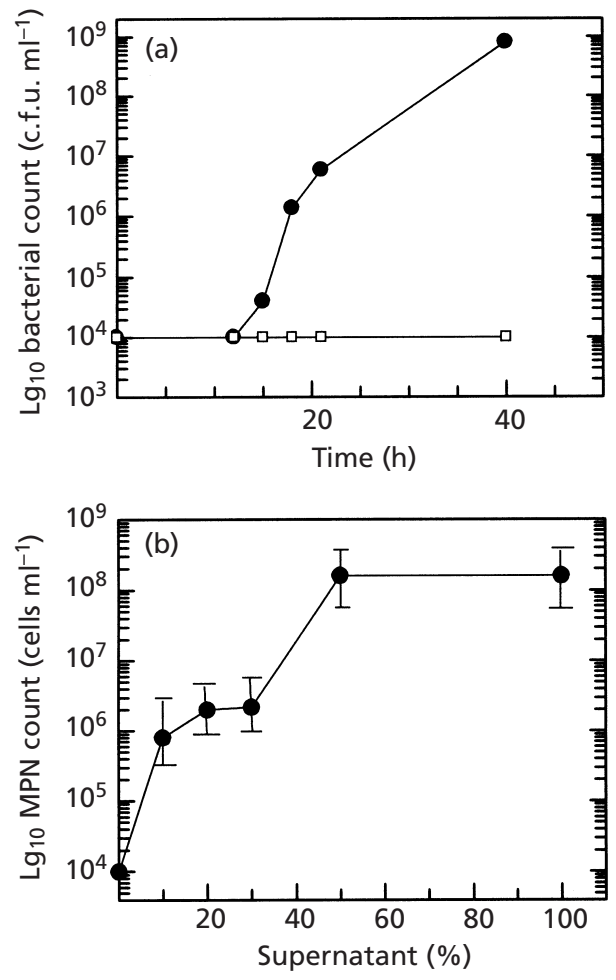

Fig. 3. Effect of culture SN on the viability of 'non-culturable' cells of $R$. rhodochrous. A culture of $R$. rhodochrous was harvested during the period of minimum culturability. (a) Bacteria were inoculated $\left(10^{6}\right.$ cells $\mathrm{ml}^{-1}$ total count) in $10 \mathrm{ml}$ of fresh modified Sauton's medium ( $\square$ ), or in filter-sterilized SN (O) taken from an exponentially growing culture. The cultures were incubated at $37^{\circ} \mathrm{C}$ (150 r.p.m.) in $30 \mathrm{ml}$ flasks; samples were then removed periodically for the determination of c.f.u. values. In (b), the MPN of the culture at the point of minimum culturability was determined in modified Sauton's medium mixed with various proportions of SN. The SD values for c.f.u. determinations were $<20 \%$. For MPN assays \pm SD values, expressed as a percentage of the mean, are shown. These experiments were repeated several times and representative results are shown.

\section{Resuscitation of 'non-culturable' cells of R. rhodochrous}

Resuscitation of cells taken during the period of nonculturability (Fig. 1a) was performed in liquid medium, using procedures previously developed for resuscitating non-culturable cells of Micrococcus luteus (Kaprelyants et al., 1994). Fig. 3(a) shows that dilution of the culture into fresh Sauton's medium containing $0.5 \%$ yeast extract followed by incubation for up to $40 \mathrm{~h}$ did not give any evidence of resuscitation. Addition of catalase $\left(3 \mu \mathrm{g} \mathrm{ml}^{-1}\right)$ or pyruvate $(0.5 \mathrm{mM})$ to the medium did not promote resuscitation either in liquid or on solid medium. Resuscitation was observed when the cells were incubated in yeast-extract-supplemented $(0.5 \%)$, filter-sterilized SN taken from a late-exponential phase culture ( $20 \mathrm{~h}$ post-inoculation) of bacteria grown in Sauton's medium (Fig. 3a). The resuscitation activity of the SN depended on its concentration; a maximal effect
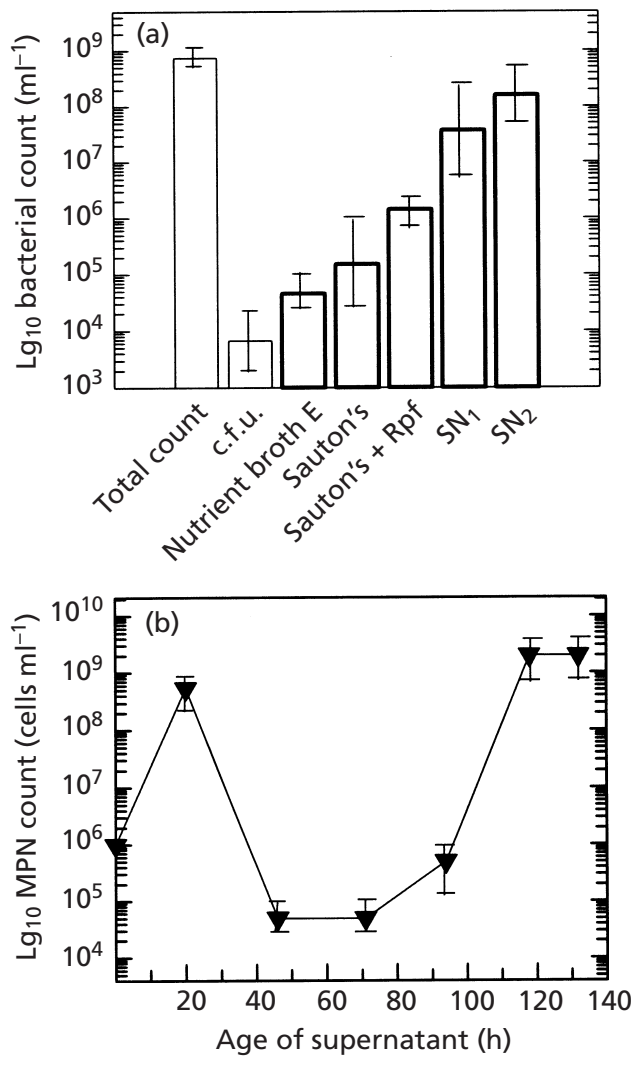

Fig. 4. Resuscitation of 'non-culturable' cells of $R$. rhodochrous. (a) An R. rhodochrous culture was harvested during the period of minimum culturability and the total and c.f.u. counts were determined. MPN assays (columns with bold outline) were performed in nutrient broth $\mathrm{E}$, modified Sauton's medium containing $0.5 \%$ yeast extract with and without recombinant Rpf $(125 \mathrm{pM})$, and $\mathrm{SN}$ taken from exponential $\left(\mathrm{SN}_{1}\right)$ and stationary phase $\left(\mathrm{SN}_{2}\right)$ cultures of $R$. rhodochrous $(18-20 \mathrm{~h}$ and 118-132 $\mathrm{h}$, respectively). The results of 35 different experiments are summarized, \pm SD. Resuscitation was also measured using SN from cultures of different ages (b). The c.f.u. and MPN values for the cells used in part (b) in the absence of SN were $1.5 \times 10^{5}$ and $1.3 \times 10^{6}$ cells $\mathrm{ml}^{-1}$, respectively. The results of a typical experiment are shown.

was observed when the proportion of $\mathrm{SN}$ to cells was $50 \%(\mathrm{v} / \mathrm{v})$ and above (Fig. 3b). For a numerical estimation of the resuscitation of 'non-culturable' cells, MPN values were determined. This procedure (Kaprelyants et al., 1994) permits true resuscitation to be distinguished from the re-growth of a small number of initially viable cells, since it occurs at high dilutions where initially viable cells are absent. Incubation of the 'non-culturable' cells in Sauton's medium resulted in a 10 -fold increase in viability measured by the MPN method when compared with c.f.u. counts (Fig. 4a). Different variations in medium composition did not result in any further increase of the MPN value. Values were similar in Sauton's medium and in a rich medium (nutrient broth E) (Fig. 4a), and the addition of ADC supplement or yeast extract at concentrations greater than $0.5 \%(\mathrm{v} / \mathrm{v})$ was inhibitory (data not shown). 
Table 1. Influence of different treatments on resuscitation activity of $\mathrm{SN}$ taken from exponentially growing cultures of $R$. rhodochrous

Bacteria were obtained from cultures during the period of minimum culturability and SN was obtained from cultures $18-20 \mathrm{~h}$ after inoculation. The 'resuscitation index' is the viability estimated as the MPN value in the presence of (treated) $\mathrm{SN}$ divided by the c.f.u. count $\left(\mathrm{MPN}_{+\mathrm{SN}} / \mathrm{c}\right.$.f.u.). The data for the anti-Rpf antibody affinity columns are from two independent experiments. All the other data represent the mean of three independent experiments \pm SD.

\begin{tabular}{|lc|}
\hline SN treatment/conditions & $\begin{array}{c}\text { 'Resuscitation } \\
\text { index' }\end{array}$ \\
\hline None & $2500 \pm 150$ \\
Control & \\
Heat & $1 \cdot 8 \pm 0 \cdot 4$ \\
Autoclaving & $110 \pm 10$ \\
Boiling 5 min & $15 \cdot 8 \pm 6 \cdot 1$ \\
Boiling 10 min & $2 \cdot 0 \pm 0 \cdot 4$ \\
Boiling 20 min & \\
Storage & $270 \pm 30$ \\
$4^{\circ} \mathrm{C}, 2$ days & $8 \cdot 5 \pm 4 \cdot 3$ \\
$4^{\circ} \mathrm{C}, 6$ days & $40 \pm 6 \cdot 6$ \\
Ambient, 1 day & \\
Trypsin & $150 \pm 50$ \\
$37^{\circ} \mathrm{C}, 30$ min & \\
Proteinase K & $10 \cdot 8 \pm 1 \cdot 1$ \\
Ambient, $1 \mathrm{~h}$ & \\
Dialysis & $310 \pm 50$ \\
$4^{\circ} \mathrm{C}$, overnight & $1 \cdot 8 \pm 0 \cdot 2$ \\
Ultra-filtration $(<10 \mathrm{kDa})$ & \\
Passage through anti-Rpf antibody & \\
column & \\
Anti-Rpf & \\
Anti-truncated Rpf & \\
\hline
\end{tabular}

However, a dramatic increase in MPN values was observed when 'non-culturable' cells were incubated in SN taken from bacterial cultures (Fig. 4a). The age of the SN was critically important. SN taken from cultures 18-20 $\mathrm{h}$ and $118-132 \mathrm{~h}$ post-inoculation was active, whereas that taken from cultures $45-70 \mathrm{~h}$ postinoculation was inactive (Fig. 4b). Moreover, the SN taken between 45 and $70 \mathrm{~h}$ contained some inhibitory material(s) that resulted in a decrease of the MPN value, compared with the value obtained in the absence of SN (Fig. 4b). The 'inhibitory' SN also suppressed the growth of exponential cells of $R$. rhodochrous (data not shown). The speed of agitation of the 48 -well plates used to measure MPN value was also critical for maximum resuscitation. The optimal speed was 150 r.p.m.; above or below this speed, the MPN value was significantly decreased.

Some properties of the resuscitation-promoting activity present in the culture $\mathrm{SN}$ are shown in Table 1.
Autoclaving or boiling the $\mathrm{SN}$ for 20 min resulted in a loss of activity. Activity was lost during storage at $4{ }^{\circ} \mathrm{C}$ over several days. The resuscitation-promoting activity was sensitive to proteolytic enzymes, removed by ultrafiltration (molecular mass $>10 \mathrm{kDa}$ ) and partially retained by dialysis (molecular mass $>10 \mathrm{kDa}$ ). The passage of the SN through affinity columns containing immobilized anti-Rpf (or anti-truncated-Rpf) antibodies resulted in a substantial loss of activity, suggesting that part of the observed resuscitation activity was due to the presence of Rpf-like proteins. This conclusion was reinforced by the finding that picomolar concentrations of recombinant Rpf also stimulated resuscitation in Sauton's medium supplemented with $0.5 \%$ yeast extract, although the effect was less pronounced than that of culture SN (Fig. 4a).

\section{Formation of 'non-culturable' cells of Mycobacterium tuberculosis}

Mycobacterium tuberculosis (Academia strain) was grown in Sauton's medium supplemented with ADC, without agitation in capped test tubes. After growth for 1 month (early-stationary phase), samples were taken periodically (one tube per time point) and the total count and c.f.u. count were estimated. Since the cells were grown in medium lacking detergent, large aggregates (and sometimes also a surface pellicle) were produced. To facilitate the manipulation of individual cells, cultures were passed through a series of filters of decreasing pore size $(20-0.45 \mu \mathrm{m})$. Moreover, we expected that cells with a non-culturable phenotype would have a reduced size, as has previously been observed with Micrococcus luteus (Mukamolova et al., 1995), Mycobacterium tuberculosis isolated from murine macrophages (Biketov et al., 2000) and R. rhodochrous (see above). The culturability of the cells (estimated as the ratio c.f.u. count/total count) decreased with decreasing filter pore size. The $1.5 \mu \mathrm{m}$ filtrate was unable to form colonies on agar (Fig. 5), despite the fact that microscopy revealed the presence of large numbers of cells (total count $4 \times 10^{7}$ cells $\mathrm{ml}^{-1}$ ).

Non-culturable cells in the $1.5 \mu \mathrm{m}$ filtrate were a mixture of ovoid cells, with a length of about $1 \cdot 1 \mu \mathrm{m}$, and small individual cocci, with a diameter of $0.5-0.7 \mu \mathrm{m}$ (Fig. $2 \mathrm{~b}$ ). Both types of cells had an intact membrane barrier (according to propidium-iodide staining) and did not reveal any respiratory activity (not stained by CTC). As seen with $R$. rhodochrous, the degree of non-culturability of the cells in the $1.5 \mu \mathrm{m}$ filtrate was time dependent (Fig. 5b). Culturability was minimal about 4 months post-inoculation, after which time the c.f.u. count gradually increased and approached the value of the total count after 8 months of cultivation. The total count of bacteria in this fraction did not change significantly during the entire period of the experiment (Fig. 5b). Oxygen availability was certainly restricted in the tube cultures used for this experiment, because incubation of Mycobacterium tuberculosis in stationary phase in oxygenated shake flasks resulted in the main- 

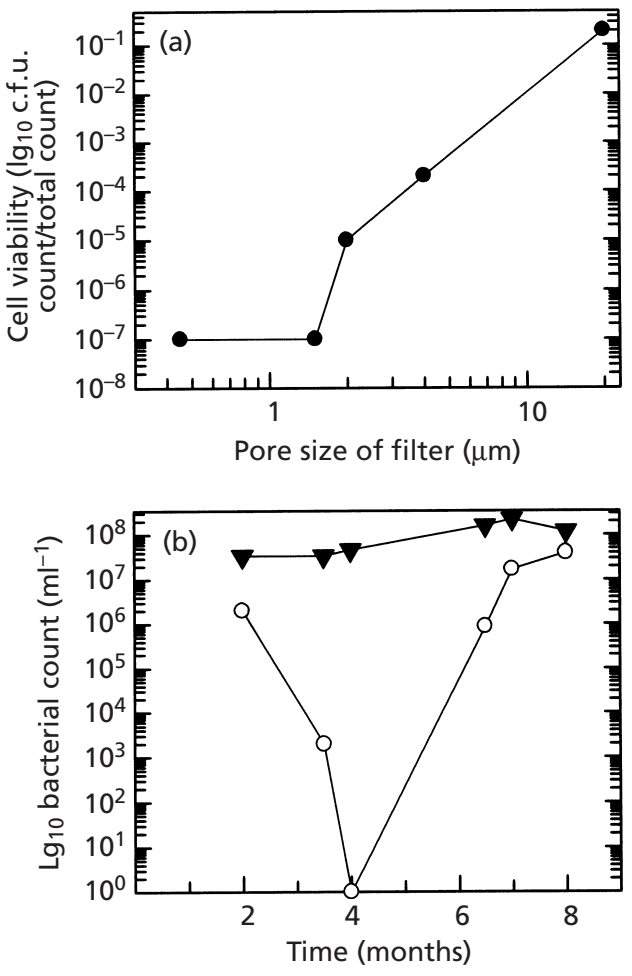

Fig. 5. Viability of Mycobacterium tuberculosis in relation to cell size and culture age. (a) A culture of Mycobacterium tuberculosis (4 months post-inoculation) was filtered consecutively through $50,4,2,1.5$ and $0.45 \mu \mathrm{m}$ filters and the c.f.u. count/total count for each of the filtrates was determined. In part (b), actively growing cells of Mycobacterium tuberculosis were inoculated $\left(10^{5}\right.$ cells $\left.\mathrm{ml}^{-1}\right)$ into Sauton's medium supplemented with ADC, and replicate cultures were incubated at $37^{\circ} \mathrm{C}$ without agitation for 8 months in capped test tubes. Periodically, samples were withdrawn and filtered through a $2 \mu \mathrm{m}$ filter. The c.f.u. ( $\bigcirc$; SD between $10 \%$ and $20 \%$ ) and total $(\boldsymbol{\nabla} ;$ SD about $17 \%)$ counts of the filtrates were determined. The results of a typical experiment are shown.

tenance of significant viability (about $10^{7}$ c.f.u. $\mathrm{ml}^{-1}$ ) of cells in the $1.5 \mu \mathrm{m}$ filtrate over a period of 8 months.

To avoid problems associated with heterogeneity, we also determined whether similar non-culturable cells could be formed in the more homogeneous cultures that are produced when Mycobacterium tuberculosis is grown in the presence of a suitable detergent. To this end, cultures were grown in flasks containing ADCsupplemented Sauton's medium with $0.05 \%$ Tween 80 , which were sealed with a rubber cap and agitated at 200 r.p.m. Sampling was done using a syringe needle to avoid introducing oxygen from the laboratory atmosphere. Under these conditions, we also found a decrease in the c.f.u. count in the total cell population, with kinetics similar to those shown in Fig. 5(b) for filtered cells. Moreover, the culture contained many of the typical ovoid and coccoid cells after 4 months of cultivation (not shown). When such cells were plated onto agar medium c.f.u. counts of zero were obtained, even after the plates were incubated for a 2 month
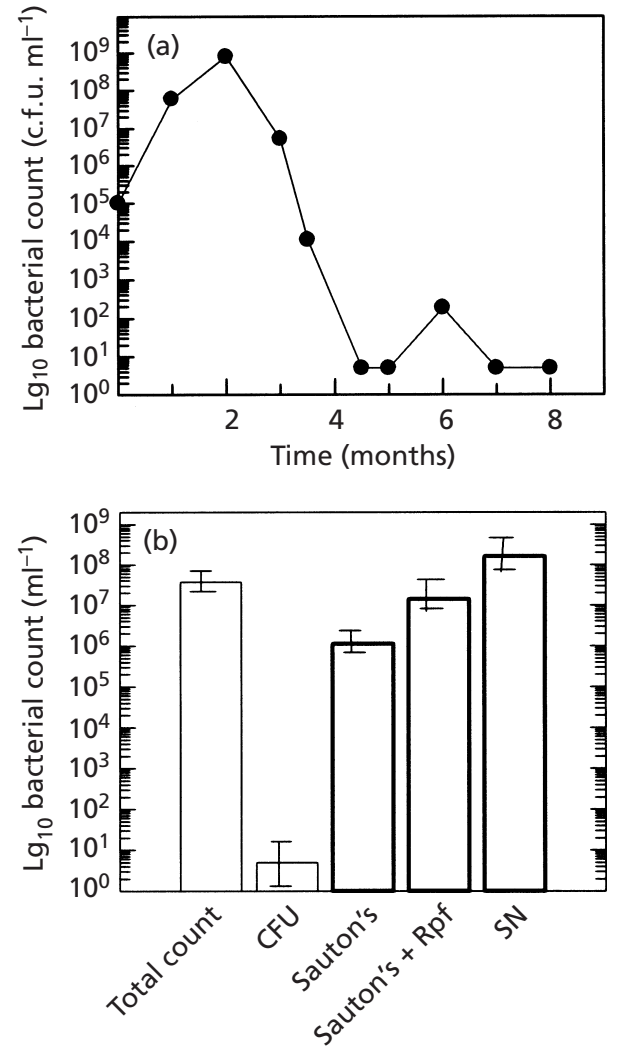

Fig. 6. Production and resuscitation of 'non-culturable' cells of Mycobacterium tuberculosis in Sauton's medium. Growing cells of Mycobacterium tuberculosis were inoculated $\left(10^{5}\right.$ cells $\left.\mathrm{ml}^{-1}\right)$ in ADC-supplemented Sauton's medium containing $0.05 \%$ Tween 80 (a) or no Tween (b) and were grown for 4-5 months, as indicated in Methods. (a) Samples of comparatively homogeneous cultures were withdrawn periodically and the c.f.u. values were determined without prior filtration (SD between $10 \%$ and $20 \%$ ). This experiment was repeated twice with similar results. In part (b), the bacterial population at 4 months (post-inoculation) was passed though a $2 \mu \mathrm{m}$ filter and the total and c.f.u. counts of the filtrate were determined. MPN assays (columns with bold outline) were performed in ADCsupplemented Sauton's medium with and without recombinant Rpf (125 pM) and also in SN taken from an actively growing culture of Mycobacterium tuberculosis (3-4 weeks postinoculation). The results of 20 independent experiments are summarized, \pm SD.

period (Fig. 6a). However, in contrast to cells grown in static culture without Tween 80, this state of nonculturability was maintained for the remainder of the experimental period (4-8 months post-inoculation).

\section{Resuscitation of 'non-culturable' cells of Mycobacterium tuberculosis}

Resuscitation of the ovoid and coccoid cells in the $1.5 \mu \mathrm{m}$ filtrate of 4-month-old cultures was performed in capped test tubes containing liquid Sauton's medium supplemented with ADC, using an MPN assay. In contrast to Micrococcus luteus or R. rhodochrous, estimation of viability in liquid medium (MPN) led to a substantial $(5 \log )$ increase in the number of viable cells 
Table 2. Resuscitation of Mycobacterium tuberculosis grown with agitation and in the presence of Tween 80

\begin{tabular}{|lcc|}
\hline \multirow{2}{*}{ Count } & \multicolumn{2}{c|}{ Culture age (months) } \\
\cline { 2 - 3 } & $\mathbf{5}$ & $\mathbf{6}$ \\
\hline Total & $7 \cdot 2 \times 10^{8}$ & $5 \cdot 6 \times 10^{8}$ \\
c.f.u. & $<5^{*}$ & $<5^{*}$ \\
MPN & $1 \cdot 1 \times 10^{5}$ & $4 \cdot 5 \times 10^{4}$ \\
MPN $_{+\mathrm{SN}}$ & $1 \cdot 0 \times 10^{6}$ & $1 \cdot 1 \times 10^{7}$ \\
\hline
\end{tabular}

* Limit of detection.

(Fig. 6b). The presence of picomolar concentrations of recombinant Rpf occasioned an additional 1-2 log increase in cell viability. SN taken from a culture of Mycobacterium tuberculosis cells growing exponentially in ADC-supplemented Sauton's medium produced an equivalent increase in the viable count. In some experiments, such as that shown in Fig. 6(b), viability estimated using the $\mathrm{SN}$ was equivalent to the total bacterial count. We were unable to obtain resuscitation of cells that passed through the $0 \cdot 45 \mu \mathrm{m}$ filters under any of the above conditions (data not shown).

Mycobacterium tuberculosis cells grown in the presence of Tween 80 were also able to resuscitate in liquid medium. Table 2 shows that 5 -month-old and 6-monthold cells, which had completely lost the ability to form colonies on solid medium, were resuscitated in liquid medium. An additional 1-2 log increase in resuscitation was obtained in the presence of SN. These results are very similar to those observed with cells obtained by filtration of heterogeneous cultures.

\section{DISCUSSION}

The phenomenon of non-culturability of bacterial cells is a matter of intensive debate [for reviews see Barer (1997), Barer \& Harwood (1999), Barer et al. (1998) and Kell et al. (1998)]. There are many publications claiming the existence of 'viable but non-culturable (VBNC)' bacteria, including several pathogenic species of bacteria. However, only in relatively few cases has the transition of such bacteria to a normal, viable (culturable) state been shown. The great majority of the experiments published to date fail to provide an unequivocal demonstration of the resuscitation of nonculturable bacteria (Kell et al., 1998). Unless such 'VBNC' cells can be resuscitated, their microbiological and medical significance must be considered highly questionable. Cells with non-culturable phenotypes may either maintain some detectable activity or persist in a dormant, inactive state. Previously we found that stationary phase cultures of Micrococcus luteus contain a large proportion of 'non-culturable' cells that remained in a dormant state for several months (Kaprelyants \& Kell, 1993a). In this study, we used similar methods to obtain non-culturable cells of R. rhodochrous and Mycobacterium tuberculosis, two members of the Corynebacterineae related to Micrococcus luteus.

As we found for Micrococcus luteus, rather strict culture conditions must be satisfied to observe the transition of the majority of the cell population to a non-culturable state (Mukamolova et al., 1998). For R. rhodochrous, inoculum age (Fig. 1b), medium composition, speed of flask agitation and culture volume in relation to the flask capacity significantly influenced the formation of nonculturable bacteria. However, in contrast to Micrococcus luteus, non-culturability was a transient phenomenon for $R$. rhodochrous cells. For each culture, there was a window of several hours during which about $99.9 \%$ of the bacteria in the culture had lost culturability. Some previously published results also show a transient decrease in the c.f.u. count when a fast-growing organism, Mycobacterium smegmatis, is held in stationary phase (Dick et al., 1998; Smeulders et al., 1999). The authors did not draw this specific conclusion from their data and considered this as a 'death' phase. Recently, Keer et al. (2000) have found that several mutants of Mycobacterium smegmatis, defective in stationary phase survival under aerobic or anaerobic conditions, revealed a transient decrease in viability followed by an increase in culturability. The authors suggest at least two possible explanations for this effect: (a) re-growth (cryptic growth) of viable cells, and (b) formation of 'non-culturable' (and possibly dormant) bacteria in stationary phase and their subsequent resuscitation (Keer et al., 2000, 2001). Since the authors did not measure culturability by MPN counts, direct evidence was neither sought nor obtained for resuscitation of non-culturable cells.

In our study, we applied MPN assays to measure viability. This method permits numerical estimation of the number of resuscitatable cells in liquid medium at high dilutions, effectively circumventing the problem of re-growth of residual viable cells during resuscitation (Kaprelyants et al., 1994; Kell et al., 1998). This assay revealed the presence of 'non-culturable' cells of $R$. rhodochrous during a rather short time interval in stationary phase. The transient character of the loss of cell viability during stationary phase suggests that there are sequential processes occurring. First, there is a transition to a 'non-culturable' state. This then seems to be followed by the (cryptic?) growth of residual viable bacteria, possibly accompanied by the growth of resuscitated bacteria after $86-96 \mathrm{~h}$ of incubation. The individual contributions of (a) residual viable cells and (b) resuscitated cells to the observed growth could vary, depending on the particular set of culture conditions (inoculum age, aeration conditions, growth medium, etc.). Non-culturable cells may be formed under many different conditions, but we have found conditions where resuscitatable cells make up the majority of the bacterial population (and are therefore experimentally accessible). Several questions remain. For example, why do R. rhodochrous cultures start to lose their culturability? Why do the viable bacteria fail to grow during the period of transition to the 'non-culturable state', and 
why do they start to grow subsequently? During the transition to 'non-culturability', we found evidence for the presence of an inhibitory component(s) in the $\mathrm{SN}$, which is no longer present once the c.f.u. counts start to increase again. Further studies are needed to elucidate the possible role of accumulation/destruction of this inhibitor in culture behaviour.

The extent of resuscitation often exceeded the proportion of active cells in the population (about $10 \%$ in all experiments, according to Rhodamine- 123 and CTC staining) and in some experiments approached $100 \%$. This fact indicates that inactive cells, with a morphology characteristic of dormancy (small coccoidal cells with enhanced phase-contrast; Mukamolova et al., 1995), can resuscitate. Therefore, we suggest that incubation of $R$. rhodochrous cells under the conditions described resulted in the formation of a population of dormant bacteria, with a characteristic 'non-culturable' phenotype.

Mycobacterium tuberculosis held in stationary phase in capped tubes also revealed the transient formation of 'non-culturable' cells (on a different time scale). However, because of the marked non-homogeneity of Mycobacterium tuberculosis cultures grown without detergent, filtration was required to isolate the fraction of non-culturable cells. The filtered fraction containing non-culturable bacteria may not include all such bacteria in the population; aggregates, unable to pass through the filter, may also contain such bacteria. The increase in the c.f.u. count after 4 months of incubation in stationary phase (Fig. 5 b) could be due to the growth of initially viable cells, to the resuscitation of non-culturable cells, or to a mixture of both of these factors in the highly heterogeneous population. The substantially homogeneous populations grown in the presence of Tween 80 were unable to form colonies for a long period of time (Fig. 6a). We suspect that it may also be possible to establish stable populations of 'non-culturable' cells for $R$. rhodochrous in stationary phase, but the appropriate conditions for this were not identified here.

There is a substantial difference between the 'nonculturable' cells of the two species studied, in respect of their ability to resuscitate. For R. rhodochrous, SN was needed for resuscitation (Fig. 4a), whereas significant resuscitation (up to 5 logs) of Mycobacterium tuberculosis cells occurred in liquid Sauton's medium without any additions (Fig. 6b). SN or Rpf further increased resuscitation of Mycobacterium tuberculosis cells by up to 2 logs (Fig. 6b). These data clearly demonstrate the fact that the term 'non-culturability' has an operational meaning only (Barer, 1997; Kell et al., 1998); Mycobacterium tuberculosis cells that were unable to form colonies on plates were able to grow in liquid medium, as was reported by Biketov et al. (2000).

As previously seen with Micrococcus luteus (Kaprelyants et al., 1994), SN taken from exponentially growing cells of both species studied possessed a 'resuscitationpromoting' activity. In R. rhodochrous SN, activity was associated with a small protein, which probably belongs to the Rpf family as $\mathrm{SN}$ passed through an affinity column containing anti-Rpf antibodies had significantly reduced activity. Indeed, immunoblotting of this SN after SDS-PAGE revealed several protein bands that interacted with specific anti-Rpf antibodies (M.O. Shleeva, unpublished results). Moreover, Southern hybridization of BamHI-, PstI-, PvuII- or XhoI-digested R. rhodochrous DNA using a rpf-specific probe revealed the presence of four hybridizing bands (data not shown). Recombinant Micrococcus luteus Rpf stimulated resuscitation of $R$. rhodochrous, but it was less active than SN.

A similar conclusion could be made with respect to the active compound in Mycobacterium tuberculosis SN, as Rpf also showed stimulatory activity (although it was less active than SN; Fig. 6b). Moreover, the Rpf-like proteins of Mycobacterium tuberculosis do indeed have growth factor activity and are able to stimulate the growth of non-culturable cells of Mycobacterium bovis BCG held in prolonged stationary phase (G.V. Mukamolova, unpublished results). In addition, 'non-culturable' cells have also been found after persistence of Mycobacterium tuberculosis in murine macrophages ex vivo. The viability of these cells was restored by incubation in the presence of $\mathrm{Rpf}$ in liquid medium (Biketov et al., 2000).

Zhang and co-workers have recently reported that nonculturable cells accumulate during prolonged incubation of Mycobacterium tuberculosis H37Ra cells in stationary phase in the presence of Tween 80 (Sun \& Zhang, 1999; Zhang et al., 2001). In contrast to our study, their cell populations contained a significant number of colony-forming units. Slight differences in culture conditions may account for this (e.g. we maintained bacteria in capped tubes without oxygen input). They showed that SN from growing Mycobacterium tuberculosis cultures contained phospholipids, which increased the number of colony-forming units in aged cultures when added to plates and permitted growth from low inocula in liquid medium. Another active compound isolated from the $\mathrm{SN}$ was an $8 \mathrm{kD}$ a protein, Rv1174c. Chemically synthesized peptides corresponding to three different segments of Rv1174c were added at micromolar concentrations (i.e. much higher than those at which Rpf is active) to liquid medium inoculated with old cells. After 5-10 days incubation, the number of recoverable colonyforming units was enhanced. We suggest that the phospholipids and micromolar concentrations of peptides employed by the authors may have promoted repair of injured cells (this may be especially true for the dried cells with zero c.f.u. counts used in this study) (Ray \& Speck, 1973). Since the authors did not measure viability by MPN, re-growth of a residual portion of viable cells cannot be excluded in some experiments and the extent of the proposed resuscitation activity cannot be quantified.

The transition of mycobacterial cells to 'dormancy' in the Wayne model in vitro is based on the formation of non-replicating bacteria during adaptation to anaerobic 


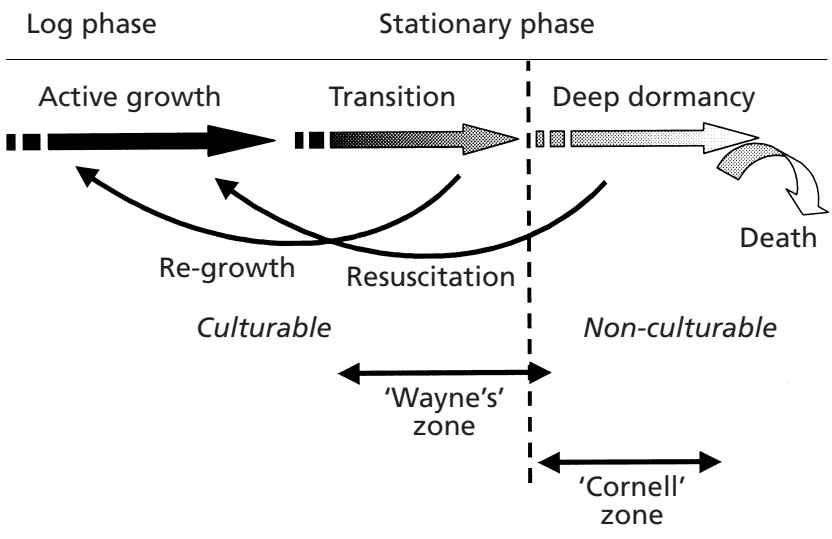

Fig. 7. A model depicting the transition of actively growing, viable bacteria to dormant forms during prolonged stationary phase. The intensity of shading of the arrows reflects the intensity of metabolic activity. The term 'non-culturable' is operational (Barer et al., 1998) and refers, in this figure, to the ability of the bacteria to form colonies.

conditions (Wayne, 1994; Wayne \& Hayes, 1996; Wayne \& Sohaskey, 2001). Protein synthesis in this state is generally reduced ( $\mathrm{Hu}$ et al., 1998), although certain genes, such as acr, are up-regulated (Desjardin et al., 2001; Hu et al., 1999; Yuan et al., 1996). The model has been established in several different species, viz. Mycobacterium tuberculosis, Mycobacterium smegmatis and Mycobacterium bovis BCG (Dick et al., 1998; Lim et al., 1999; Wayne, 1994). However, in contrast to our study, mycobacterial cells in Wayne's model retain high viability and develop sensitivity to metronidazole as they become anaerobic (Wayne \& Sramek, 1994), indicating that they remain metabolically active. Therefore, they may not be considered truly dormant, but rather in a state of $\left(\mathrm{O}_{2}\right)$ starvation-survival (Kaprelyants et al., 1993). We suggest that the difference in culturability may reflect the different times of persistence of Mycobacterium tuberculosis cells in a non-growing state (days in Wayne's model and months in our study). Restoration of culturability requires resuscitation in liquid medium, which may either occur spontaneously or require the provision of compounds (e.g. growth factors) present in the $\mathrm{SN}$ of growing cells. The proportion of cells able to resuscitate spontaneously and those requiring growth factors may vary from one experiment to another, and resuscitation may depend on the particular conditions employed for the establishment of 'non-culturability'.

Prolonged incubation of Mycobacterium tuberculosis cells in stationary phase may reflect more accurately the situation in vivo. In this connection we may stress that the essence of the Cornell model of dormant Mycobacterium tuberculosis is the creation of a period of 'sterility' in vivo, induced by the administration of antibiotics after infection, when Mycobacterium tuberculosis cannot be detected by c.f.u. counts (Wayne, 1994) (in contrast to PCR; de Wit et al., 1995). As shown in Fig. 7, Wayne's model may possibly represent a step towards the establishment of true dormancy in $\mathrm{Myco-}$ bacterium tuberculosis, which is characterized by the emergence of 'non-culturable' cells that need to be resuscitated before they can resume active growth. The necessity for anaerobic conditions to produce 'nonculturable' cells of Mycobacterium tuberculosis in our experiments may reflect a mechanistic link between Wayne's model and the model employed here. More work is required to establish whether the proposed sequence of events does indeed take place during the transition to, and reactivation from, the latent state in vivo. The observed activity of SN or Rpf with 'nonculturable' bacterial populations suggests that one or more of the cognate Mycobacterium tuberculosis proteins could be involved in mechanisms of latency and reactivation of tuberculosis in vivo.

\section{ACKNOWLEDGEMENTS}

We thank the Wellcome Trust (grant no. 055840), the UK Biotechnology and Biological Sciences Research Council and The Russian Foundation for Basic Research (grants 00-04-48691 and 01-04-06180mas) for their financial support.

\section{REFERENCES}

Barer, M. R. (1997). Viable but non-culturable and dormant bacteria: time to resolve an oxymoron and a misnomer? J Med Microbiol 46, 629-631.

Barer, M. R. \& Harwood, C. R. (1999). Bacterial viability and culturability. Adv Microb Physiol 41, 93-137.

Barer, M. R., Kaprelyants, A. S., Weichart, D. H., Harwood, C. R. \& Kell, D. B. (1998). Microbial stress and culturability: conceptual and operational domains. Microbiology 144, 2009-2010.

Biketov, S., Mukamolova, G. V., Potapov, V., Gilenkov, E., Vostroknutova, G., Kell, D. B., Young, M. \& Kaprelyants, A. S. (2000). Culturability of Mycobacterium tuberculosis cells isolated from murine macrophages: a bacterial growth factor promotes recovery. FEMS Immunol Med Microbiol 29, 233-240.

Connell, N. D. (1994). Mycobacterium: isolation, maintenance, transformation, and mutant selection. Methods Cell Biol 45, 107-125.

Cunningham, A. F. \& Spreadbury, C. L. (1998). Mycobacterial stationary phase induced by low oxygen tension: cell wall thickening and localization of the 16-kilodalton $\alpha$-crystallin homolog. J Bacteriol 180, 801-808.

Davey, H. M., Kaprelyants, A. S., Weichart, D. H. \& Kell, D. B. (1999). Approaches to the estimation of microbial viability using flow cytometry. In Current Protocols in Cytometry, vol. 11, Microbial Cytometry. Edited by J. P. Robinson. New York: Wiley.

de Man, J. C. (1975). The probability of most probable numbers. Eur J Appl Microbiol 1, 67-78.

de Wit, D., Wootton, M., Dhillon, J. \& Mitchison, D. A. (1995). The bacterial DNA content of mouse organs in the Cornell model of dormant tuberculosis. Tuber Lung Dis 76, 555-562.

Desjardin, L. E., Hayes, L. G., Sohaskey, C. D., Wayne, L. G. \& Eisenach, K. D. (2001). Microaerophilic induction of the alphacrystallin chaperone protein homologue ( $h s p X) \mathrm{mRNA}$ of $\mathrm{Myco-}$ bacterium tuberculosis. J Bacteriol 183, 5311-5316.

Dick, T., Lee, B. H. \& Murugasu-Oei, B. (1998). Oxygen depletion 
induced dormancy in Mycobacterium smegmatis. FEMS Microbiol Lett 163, 159-164.

Flynn, J. L. \& Chan, J. (2001). Tuberculosis: latency and reactivation. Infect Immun 69, 4195-4201.

Gangadharam, P. R. J. (1995). Mycobacterial dormancy. Tuber Lung Dis 76, 477-479.

Hu, Y. M., Butcher, P. D., Sole, K., Mitchison, D. A. \& Coates, A. R. M. (1998). Protein synthesis is shut down in dormant Mycobacterium tuberculosis and is reversed by oxygen or heat shock. FEMS Microbiol Lett 158, 139-145.

Hu, Y., Butcher, P. D., Mangan, J. A., Rajandream, M. A. \& Coates, A. R. (1999). Regulation of $h m p$ gene transcription in Mycobacterium tuberculosis: effects of oxygen limitation and nitrosative and oxidative stress. J Bacteriol 181, 3486-3493.

Hutter, B. \& Dick, T. (1998). Increased alanine dehydrogenase activity during dormancy in Mycobacterium smegmatis. FEMS Microbiol Lett 167, 7-11.

Kaprelyants, A. S. \& Kell, D. B. (1992). Rapid assessment of bacterial viability and vitality using rhodamine 123 and flow cytometry. J Appl Bacteriol 72, 410-422.

Kaprelyants, A. S. \& Kell, D. B. (1993a). Dormancy in stationaryphase cultures of Micrococcus luteus: flow cytometric analysis of starvation and resuscitation. Appl Environ Microbiol 59, 31873196.

Kaprelyants, A. S. \& Kell, D. B. (1993b). The use of 5-cyano-2,3ditolyl tetrazolium chloride and flow-cytometry for the visualization of respiratory activity in individual cells of Micrococcus luteus. J Microbiol Methods 17, 115-122.

Kaprelyants, A. S. \& Kell, D. B. (1996). Do bacteria need to communicate with each other for growth? Trends Microbiol 4, 237-242.

Kaprelyants, A. S., Gottschal, J. C. \& Kell, D. B. (1993). Dormancy in non-sporulating bacteria. FEMS Microbiol Rev 104, 271-286.

Kaprelyants, A. S., Mukamolova, G. V. \& Kell, D. B. (1994). Estimation of dormant Micrococcus luteus cells by penicillin lysis and by resuscitation in cell-free spent medium at high dilution. FEMS Microbiol Lett 115, 347-352.

Kaprelyants, A. S., Mukamolova, G. V., Davey, H. M. \& Kell, D. B. (1996). Quantitative analysis of the physiological heterogeneity within starved cultures of Micrococcus luteus by flow cytometry and cell sorting. Appl Environ Microbiol 62, 1311-1316.

Kaprelyants, A. S., Mukamolova, G. V., Kormer, S. S., Weichart, D. H., Young, M. \& Kell, D. B. (1999). Intercellular signalling and the multiplication of prokaryotes: bacterial cytokines. In $\mathrm{Mi}$ crobial Signalling and Communication (Society for General Microbiology Symposium no. 57), pp. 33-69. Edited by R. England, G. Hobbs, N. Bainton \& D. McL. Roberts. Cambridge: Cambridge University Press.

Keer, J., Smeulders, M. J., Gray, K. M. \& Williams, H. D. (2000). Mutants of Mycobacterium smegmatis impaired in stationaryphase survival. Microbiology 146, 2209-2217.

Keer, J., Smeulders, M. J. \& Williams, H. D. (2001). A purF mutant of Mycobacterium smegmatis has impaired survival during oxygen-starved stationary phase. Microbiology 147, 473-481.

Kell, D. B. \& Young, M. (2000). Bacterial dormancy and culturability: the role of autocrine growth factors. Curr Opin Microbiol 3, 238-243.
Kell, D. B., Kaprelyants, A. S., Weichart, D. H., Harwood, C. L. \& Barer, M. R. (1998). Viability and activity in readily culturable bacteria: a review and discussion of the practical issues. Antonie Leeuwenhoek 73, 169-187.

Lim, A., Eleuterio, M., Hutter, B., Murugasu-Oei, B. \& Dick, T. (1999). Oxygen depletion-induced dormancy in Mycobacterium bovis BCG. J Bacteriol 181, 2252-2256.

McCune, R. M., Feldman, F. M., Lambert, H. \& McDermott, W. (1966). Microbial persistence. I. The capacity of tubercle bacilli to survive sterilization in mouse tissues. J Exp Med 123, 224-268.

Mukamolova, G. V., Yanopolskaya, N. D., Votyakova, T. V., Popov, V. I., Kaprelyants, A. S. \& Kell, D. B. (1995). Biochemical changes accompanying the long-term starvation of Micrococcus luteus cells in spent growth medium. Arch Microbiol 163, 373-379.

Mukamolova, G. V., Kaprelyants, A. S., Young, D. I., Young, M. \& Kell, D. B. (1998). A bacterial cytokine. Proc Natl Acad Sci U S A 95, 8916-8921.

Ogloblina, L. S. \& Ravich-Birger, E. D. (1958). Catalogue of Strains, issue 2, p. 6. Moscow: Tarasevich State Control Institute of Medical and Biological Preparations.

Osterman, I. (1985). Chromatography of Proteins and Nucleic Acids. Moscow: Nauka.

Parrish, N. M., Dick, J. D. \& Bishai, W. R. (1998). Mechanisms of latency in Mycobacterium tuberculosis. Trends Microbiol 6, 107-112.

Ray, B. \& Speck, M. L. (1973). Freeze-injury in bacteria. CRC Crit Rev Clin Lab Sci 4, 161-213.

Smeulders, M. J., Keer, J., Speight, R. A. \& Williams, H. D. (1999). Adaptation of Mycobacterium smegmatis to stationary phase. $J$ Bacteriol 181, 270-283.

Sun, Z. \& Zhang, Y. (1999). Spent culture supernatant of Mycobacterium tuberculosis H37Ra improves viability of aged cultures of this strain and allows small inocula to initiate growth. J Bacteriol 181, 7626-7628.

Wayne, L. G. (1994). Dormancy of Mycobacterium tuberculosis and latency of disease. Eur J Clin Microbiol Infect Dis 13, 908-914.

Wayne, L. G. \& Hayes, L. G. (1996). An in vitro model for sequential study of shiftdown of Mycobacterium tuberculosis through 2 stages of nonreplicating persistence. Infect Immun 64, 2062-2069.

Wayne, L. G. \& Sohaskey, C. D. (2001). Nonreplicating persistence of Mycobacterium tuberculosis. Annu Rev Microbiol 55, 139163.

Wayne, L. G. \& Sramek, H. A. (1994). Metronidazole is bactericidal to dormant cells of Mycobacterium tuberculosis. Antimicrob Agents Chemother 38, 2054-2058.

Yuan, Y., Crane, D. D. \& Barry III, C. E. (1996). Stationary phaseassociated protein expression in Mycobacterium tuberculosis: function of the mycobacterial alpha-crystallin homolog. $\mathrm{J} \mathrm{Bac-}$ teriol 178, 4484-4492.

Zhang, Y., Yang, Y., Woods, A., Cotter, R. J. \& Sun, Z. (2001). Resuscitation of dormant Mycobacterium tuberculosis by phospholipids or specific peptides. Biochem Biophys Res Commun 284, 542-547.

Received 24 October 2001; revised 10 December 2001; accepted 8 January 2002. 